I/Ioth of an inch in diameter, and are spherical or oblong in form, the translucent membrane appearing under the microscope to be composed of minute particles and spicules imbedded therein.

As my observations included the examination of surface-life, the tow-net was continuously employed, and was always rapidly filled with so much gelatinous substance that it was difficult to pick out the Copepoda or other pelagic life. But although all of the bodies were perfect in form when taken in a bottle, the rush of water into the tow-net was sufficient to fracture them, the result being a mass of broken gelatinous débris (apparently vegetable) which clung tenaciously to the muslin of the net.

They appeared to be most numerous a few feet below the surface, and are distinctly visible on looking down into the water from the boat-side. Weather does not seem to affect them, being apparently equally prevalent on a calm or a rough day; but I noticed while rowing across from Penmaenmaur to Puffin Island, a distance of seven miles, that they were less plentiful about the middle of the entrance to the Menai Straits than nearer each side.

Early in June they were in profusion about the mouth of the Dee. Associated with them I have invariably found quantities of Noctiluca, which soon congregated about the surface of the collecting-jar, while the gelatinous spheres remained suspended in the water, and the débris from the tow-net fell to the bottom.

Any light that can be thrown upon the nature and appearance of these curious bodies will be much esteemed.

Liverpool, July 16

IsAaC C. Thompson

\section{The Banner System of Drainage}

OUR attention has been called to a paragraph in NATURE (p. 22I) in which you review, "Hygiene, a Manual of Personal and Public Health," by A. Newsholme, M.D., Lond. In your review or criticism you state that you "do not agree with Dr. Newsholme in thinking the "Banner system of drainage one to be recommended," "and you say your system coincides with that of several practical sanitarians. Now, as this is calculated to do harm, and as our system has been approved of by the most eminent sanitarians, and has also obtained the highest awards at all the most important exhibitions, including a Gold Medal at the Health Exhibition, I884, and has been successfully applied to many noblemen's mansions, hospitals, and other important public buildings, as well as to thousands of houses, we hope you will think we are justified in asking you to tell us your reasons for expressing the unfavourable opinion you have, and that you will oblige us with the names of the "practical sanitarians" you refer to.

We are unacquainted with Dr. Newsholme, and until the paragraph in NATURE was pointed out to us we were not aware of the existence of such a gentleman. Nevertheless, in fairness to him as well as to the public, we will thank you to insert this in your next issue.

Banner Brothers and Co., per MANAGER

\section{I, Billiter Square, E.C., July I4}

[Exception having been taken by Messrs. Banner \& Co. to a statement which appeared in our last issue in the review of the Elementary Text-books of hygiene, having reference to this system, we have no objection to state that (in the opinion of our reviewer) the Banner system, although correct in principle, is unnecessarily complicated in the details of its working. The "Banner Patent Closet" shown in diagram in the book referred to is a modification of the pan-closet, a closet which has been universally condemned and as almost universally acknowledged to be incapable of improvement. - ED.]

\section{ON THE USE OF CARBON BISULPHIDE IN PRISMS ${ }^{1}$}

IN the American Journal of Science for April, I885, there is an account of some experiments of Dr. Draper's which will be read with great interest by all who have used liquid prisms in a spectroscope. The following is an abstract of the article :-

The photographs which were taken in the research on the presence of oxygen in the sun were obtained by the 1 Being an account of experiments made by the late Dr. Henry Draper, use of two hollow prisms filled with carbon bisulphide. The same prisms had been used by Mr. Rutherford to produce his celebrated solar prismatic spectrum. The photographic work for the oxygen research was done in New York in a back room of the third storey of Dr. Draper's residence. The temperature of the room was remarkably uniform and the definition was all that could be desired. When, however, the research was continued in the new physical laboratory which Dr. Draper completed in $\mathrm{I} 880$, it was found practically impossible to use carbon bisulphide prisms in the room owing to the rapid variations of temperature. No definition whatever could be obtained with the same prisms which had performed so well previously. In consequence the use of these prisms had to be abandoned and a series of experiments made to obtain the spectrum by other means. A Rutherford silvered glass grating of 8640 lines to the inch and a train of six flint glass prisms made by Steinheil were each tried. The grating was not found satisfactory, partly because want of light rendered long exposure necessary, partly because the definition was not so good as had been originally obtained from the bisulphide prisms. The flint prisms gave excellent definition, quite as good as had been obtained with the bisulphide prisms, but there was less light, and it was found impossible to get the line $\mathrm{H}$ on the photographic plate, through the train. The dispersion between $G$ and $H$ with the six flint prisms was not quite so great as with the two bisulphide of carbon prisms.

Among the earliest experiments which were undertaken in the new laboratory was a series made to test the performance of a bisulphide prism of Thollon's construction, made by Hilger, of London. This prisms consists of a glass bottle having two plane sides, making an angle of $90^{\circ}$ with one another, upon which are cemented two prisms of flint glass 4 by 2 inches on the face, having each a refracting angle of $18^{\circ}$. The refracting edges of these glass prisms are opposed to that of the bisulphide prism. Hence the refracting angle of the compound prism is $54^{\circ}$. The same difficulties were experienced with this prism as with the Rutherford bisulphide prism. Owing to the temperature variations the lines were "woolly" and no definition was possible. It was found that the dispersion power of the Thollon prism was equal to that of about four of the Steinheil flint prisms ; and this fact, together with the unsatisfactory character of the results obtained with the train of prisms as well as with the grating, led Dr. Draper to undertake an investigation into the cause of this unsteadiness of the bisulphide with a view to remedying it if practicable.

While using these prisms Mr. Rutherford made an important observation. He noticed that if a good prism which, with a high power, refuses to define the soda line (a more stringent test than soda lines), is violently shaken and then placed in position, it will for a few minutes define beautifully, but gradually settle to its former condition.

It occurred to Dr. Draper, therefore, that possibly the striæ caused by convection-currents produced by inequalities of temperature, and which caused the bad definition, might be destroyed by an active agitation of the liquid. He therefore placed a small propeller wheel in the bisulphide contained in the Thollon prism, passing its shaft through the stopper so that he could drive it at any desired speed by an electro-motor. The result was marvellous: by thus keeping the liquid in agitation all inequalities in its density were prevented, and the definition became excellent. Thus arranged, the Thollon prism was found to be superior, especially in quantity of light, to the Steinheil train of prisms.

Now another source of error was developed. Although when the propeller was running the definition of the bisulphide was not affected by changes of temperature, yet now these changes of temperature, by changing the refractive index of the liquid, caused a continual shifting of 